\title{
General evaluation of periventricular-intraventricular hemorrhage in premature infants in mainland China
}

\author{
Çin'de prematür infantlardaki periventriküler-intraventriküler hemorajiler \\ hakkında genel bilgiler
}

\author{
Jing Liu' ${ }^{1}$ Li-wen Chang ${ }^{2}$, Qi Wang ${ }^{3}$, Gui-lian Qin ${ }^{4}$ \\ 'Department of Neonatology \& Nicu, Bayi Children's Hospital Affiliated With Beijing Military Region General Hospital, \\ Beijing, China \\ ${ }^{2}$ Department of Pediatrics, Tongji Hospital Affilitiated To Tongji Medical College, Huazhong University of Science and \\ Technology, Wuhan, China \\ ${ }^{3}$ Beijing Obstetrics and Gynecology Hospital, Capital Medical University, Beïing, China \\ ${ }^{4}$ Qinhuangdao Maternity and Infants' Hospital, Qinhuangdao, Hebei Province, China
}

\section{Abstract}

Objective: To explore the incidence and analyze the high risk factors of PIVH in premature infants in mainland China.

Materials and Methods: A total of 1122 premature infants at $<37$ weeks gestation were enrolled in this study. All the infants received intracranial ultrasound examinations within 1 week after birth,and the perinatal data were recorded to analyze the high risk factors for PIVH. Results: The results showed that the incidence rate of PIVH was $55.2 \%$ in mainland Chinese population. Among these cases, mild degrees of PIVH accounted for $82.2 \%$ and severe degrees of PIVH accounted for only $17.8 \%$. The most important risk factors related to PIVH were low gestational age, low birth weight, low Apgar score and ventilatory treatment, etc.

Conclusions: It suggested that there were many high risk factors related to PIVH in premature infants and a screening cutoff point of 2000 g appeared to be more adequate for China.

(J Turkish-German Gynecol Assoc 2010; 11: 73-7)

Key words: Periventricular-intraventricular hemorrhage, premature infant, risk factors, Chinese population

Received: 6 December, 2009

Accepted: 4 February, 2010

\section{Özet}

Amaç: Çin'de prematur infantlardaki PIVH insidansını araştırmak ve analiz etmek.

Gereç ve Yöntemler: Otuzyedi hafta öncesinde doğmuş 1122 prematur infant çalışmaya dahil edildi. Tüm bu bebekler doğumdan 1 hafta sonra intrakranial ultrasonografi incelemesine tabii tutuldu ve perinatal bilgileri PIVH için risk faktörlerinin analiz etmek için kaydedildi.

Bulgular: Ana Çin populasyonunda PIVH insidansı \%55.2 olarak saptandı. Bu olgularda hafif PIVH oranı \%82.2, ağır PIVH ise \%17.8 olarak saptandı. PIVH için en önemli risk faktörleri erken gebelik haftalanı, düşük doğum kilosu, düşük Apgar skoru ve ventilatuar tedaviler vb. olarak belirlendi.

Sonuç: Öyle görünmektedir ki prematur infantlardaki PIVH gelişimi için birçok risk faktörü bulunmaktadır. Çin'de PIVH taraması için $2000 \mathrm{~g}$ bebek ağırlığı eşik değer olarak uygundur.

(J Turkish-German Gynecol Assoc 2010; 11: 73-7)

Anahtar kelimeler: Periventriküler-intraventriküler hemoraji, prematur infant, risk faktörleri, Çin populasyonu

Geliş Tarihi: 06 Aralık 2009

Kabul Tarihi: 04 Şubat, 2010

\section{Introduction}

Periventricular-intraventricular hemorrhage (PIVH) is a common disease in premature infants and one of the most important causes of mortality and disabilities, including cerebral palsy and neurodevelopmental delay, even in patients with milder grades of PIVH (1-3). Although the incidence of PIVH has declined over the past two decades from $30-40 \%$ in the early 1980 s to $<20 \%$ in the 1990 s in developed countries (4-8), there is a lack of general data concerning PIVH in China, the largest developing country. The aims of the present study were to explore the incidence of PIVH and analyze its high risk factors in premature infants, and to suggest a working protocol for PIVH diagnosis, prevention and treatment in newborn infants at risk.

\section{Materials and Methods}

\section{Patients}

This study was a cohort prospective study involving 1122 premature infants (594 males; 528 females) delivered at $<37$ and $>26$ weeks of gestation at the Beijing Obstetrics \& Gynecol- 
ogy Hospital and Qinhuangdao Maternity and Infants' Hospital from January 2002 to June 2005. Among all the newborn infants, the mean gestational age was $31.9 \pm 2.1$ weeks and the mean birth weight was $1997 \pm 523 \mathrm{~g}$.

\section{Ultrasound criteria}

Ultrasound examinations were carried out during the first week after birth. Intraventricular hemorrhage was diagnosed sonographically,based on the classification by Papile (9) as follows: Grade I, germinal matrix hemorrhage with no or minimal intraventricular hemorrhage; Grade II: intraventricular hemorrhage without ventricular dilatation; Grade III: intraventricular hemorrhage with primary ventricular dilatation; Grade IV: intraventricular hemorrhage and intraparenchymatous hemorrhage. Mild degrees of hemorrhage were defined as Grades I and II, while severe degrees of hemorrhage were defined as Grades III and IV.

\section{Clinical data collection}

The study recorded various kinds of perinatal data including maternal complications (pregnancy-induced hypertension, chronic hypertension, diabetes, anemia, etc.), premature rupture of fetal membranes, fetal distress, mode of delivery, gestational age, asphyxia, Apgar score, birth weight, sex, multiple birth, body temperature of $\leq 35.5^{\circ} \mathrm{C}$, antenatal corticosteroid use, presence of respiratory distress and need for ventilatory treatment, anemia, blood $\mathrm{pH} \leq 7.20, \mathrm{SaO}_{2}<85 \%, \mathrm{PaCO}_{2} \geq 7.33 \mathrm{kPa}$, serum osmolality, hyperlactacidemia and platelet parameters.

Pregnant women at high risk for preterm birth at a gestational age of $<35$ weeks were randomly divided into two groups according to their in-patient registration numbers of theBeijing Military Region General Hospital. Pregnant women in the vitamin $K_{1}$ group received antenatal injections of vitamin $K_{1}$ at 10 $\mathrm{mg} /$ day intramuscularly or intravenously for 2 to 7 days. Women in the control group were not given vitamin $\mathrm{K}_{1}$ injections. The women in the two groups had similar ages, domestic economic statuses, prenatal complications and routes of delivery. Besides, the infants were divided into phenobarbital and non-phenobarbital groups as well according to the in-patient registration number after birth. The infants in the phenobarbital group received an intravenous injection of phenobarbital at $20 \mathrm{mg} / \mathrm{kg}$ within 2 hours after birth, followed by injections at $5 \mathrm{mg} / \mathrm{kg}$ every 12 hours for 3 days. The infants in the non-phenobarbital group did not receive any phenobarbital injections after birth. And the study protocol was approved by the research committee of the Beijing Military Region General Hospital.

To understand the blood count data, 50 healthy term infants without PIVH or any other diseases were selected as healthy controls. Their data were compared with the platelet parameters of the premature infants with PIVH to clarify whether abnormal platelet parameters have an influence on PIVH.

\section{Statistical analysis}

Data analyses were conducted with SPSS12.0 for Windows. Differences among the incidences of PIVH between the groups were assessed with $\chi^{2}$ tests, one-way ANOVA or $t$-tests.

\section{Results}

Total incidence of PIVH in premature infants

The total incidence of PIVH in the study population was $55.2 \%$ (619/1122). Among the 619 cases, low degrees of PIVH accounted for $82.2 \%$ and severe degrees of PIVH accounted for $17.8 \%$.

Correlation between gestational age and the incidence of PIVH The incidences of PIVH were 78.5\% (197/251) among infants at $<32$ gestational weeks, $57.1 \%(287 / 503)$ among infants at $<32 \sim 35$ gestational weeks and 36.7\% (135/368) among infants at $<35 \sim 37$ gestational weeks. These data indicated that lower gestational ages were associated with higher incidences of PIVH. Among the 110 cases with severe PIVH, 79 were at $<32$ weeks, 27 at $<35$ weeks and only 4 at $\geq 35$ weeks. These data indicated that lower gestational ages were associated with more severe degrees of PIVH.

\section{Correlation between birthweight and the incidence of PIVH}

As shown in Table 1, lower birthweights were associated with higher incidences of $\mathrm{PIVH}$, and the incidences were especially high among infants with birthweights of $<2000 \mathrm{~g}$.

Correlation between mode of delivery and the incidence of PIVH The incidences of PIVH were $52.7 \%$ in the cesarean section group and $57.2 \%$ in the vaginal delivery group. These data indicated that delivery mode was not associated with $\mathrm{PIVH}$ $\left(\chi^{2}=1.15, p=0.283\right)$.

Correlation between multiple births and the incidence of PIVH The incidences of PIVH were 57.4\% in the multiple birth group and $54.8 \%$ in the single birth group. These data indicated that multiple births did not significantly increase the incidence of $\operatorname{PIVH}\left(\chi^{2}=0.11, p=0.740\right)$.

Correlation between use of antenatal corticosteroids and the incidence of PIVH

Use of antenatal corticosteroids significantly reduced the incidence of PIVH in infants at $<35$ weeks, but had no marked influence on infants at $\geq 35$ weeks (Table 2 ).

Effect of postnatal administration of phenobarbital on the incidence of PIVH

During the study, we examined the effect of postnatal administration of phenobarbital on the incidence of PIVH. Among 112 pre-

Table 1. Incidences of PIVH among infants with different birthweights

\begin{tabular}{|l|c|c|c|}
\hline birthweight (g) & $\mathbf{n}$ & PIVH (n) & incidence rate (\%) \\
\hline$\leq 1250$ & 102 & 77 & 75.5 \\
\hline$\sim 1500$ & 138 & 94 & 68.1 \\
\hline$\sim 2000$ & 308 & 192 & 62.3 \\
\hline$\sim 2500$ & 379 & 189 & 49.9 \\
\hline$>2500$ & 195 & 67 & 34.4 \\
\hline$\chi^{2}=28.96, p<0.001$ & \multicolumn{3}{|l}{} \\
\end{tabular}


term infants, 50 were divided into a phenobarbital-treated group and 62 were divided into a control group. Administration of phenobarbital was carried out at $<2$ hours after birth. Although the total incidences of PIVH were $52.0 \%$ in the phenobarbital group and $56.4 \%$ in the non-phenobarbital group $\left(\chi^{2}=0.221, p=0.638\right)$, the incidence of severe PIVH was markedly decreased in the phenobarbital group (4.0\% vs. $17.7 \%, \chi^{2}=5.09, p=0.024$ ).

Influence of maternal perinatal complications on the incidence of PIVH Maternal complications in the perinatal period significantly increased the incidence of PIVH among infants at $<35$ weeks, but not among infants at $\geq 35$ weeks (Table 3 ).

Influence of fetal distress and birth asphyxia on the incidence of PIVH The incidences of PIVH were $67.4 \%$ and $49.0 \%$ in preterm infants with and without fetal distress and birth asphyxia, respectively $\left(\chi^{2}=5.52, p=0.019\right)$.

Mechanical ventilation and the incidence of PIVH

Mechanical ventilation significantly increased the incidence of PIVH from $52.2 \%$ to $82.2 \%\left(\chi^{2}=13.79, p<0.001\right)$.

\section{Hypoglycemia and the incidence of PIVH}

The incidence of PIVH was much higher in infants with hypoglycemia than in infants without hypoglycemia (61.0\% vs. $51.7 \%$, $\left.\chi^{2}=5.99, p=0.014\right)$.

Serum osmolality and the incidence of PIVH

The serum osmolalities in the groups with and without PIVH were $292.7 \pm 9.77$ and $293.9 \pm 8.83 \mathrm{mOsm} / \mathrm{L}$, respectively, and showed no significant difference $(t=1.01, p=0.335)$.

Hypoxia, acidosis and hypercapnia and the incidence of PIVH The incidence of PIVH was much higher in infants with hypoxia $\left(\mathrm{SaO}_{2}<85 \%\right)$ than in infants without hypoxia (61.8\% vs. $53.3 \%$, $\chi^{2}=4.095, p=0.043$ ). Acidosis (blood $\mathrm{pH} \leq 7.20$ ) significantly increased the incidence of PIVH in preterm infants from $49.9 \%$ to $58.5 \%\left(\chi^{2}=5.206, p=0.023\right)$. Hypercapnia $\left(\mathrm{PaCO}_{2} \geq 7.33 \mathrm{kPa}\right)$ was also a high risk factor for PIVH, and increased the incidence of PIVH from $51.9 \%$ to $61.0 \%\left(\chi^{2}=3.837, p=0.05\right)$.

Correlation between hyperlactacidemia and the incidence of PIVH The incidences of PIVH were $61.7 \%$ and $50.1 \%$ in the hyperlactacidemia and normal serum lactic acid groups, respectively $\left(\chi^{2}=9.173, p=0.002\right)$.

Correlation between premature rupture of fetal membranes and the incidence of PIVH

The incidences of PIVH were $60.2 \%$ and $49.9 \%$ in infants with and without premature rupture of fetal membranes, respectively $\left(\chi^{2}=9.380, p=0.002\right)$.

\section{Hypothermia and the incidence of PIVH}

Hypothermia (body temperature of $\leq 35.5^{\circ} \mathrm{C}$ ) increased the incidence of PIVH in preterm infants from $54.1 \%$ to $65.1 \%\left(\chi^{2}=5.87\right.$, $p=0.017$ )

Maternal antenatal administration of vitamin $K_{1}$ and the incidence of PIVH

Maternal antenatal administration of vitamin $\mathrm{K}_{1}$ decreased the incidence of PIVH in preterm infants from $54.0 \%$ to $32.5 \%$ $\left(\chi^{2}=4.16, p=0.041\right)$.

Correlations between platelet parameters and the incidence of PIVH

The platelet parameters examined included platelet counts (PLT; $\left.\times 10^{9} / \mathrm{L}\right)$, thrombocytocrit (PCT; \%), mean platelet volume (MPV; fl) and platelet distribution width (MPV; \%). These parameters were determined in 100 premature infants with $\mathrm{PIVH}, 60$ premature infants without PIVH and 50 healthy term

Table 2. Correlation between antenatal corticosteroid use and PIVH

\begin{tabular}{|c|c|c|c|c|c|c|}
\hline \multirow[t]{2}{*}{ Groups } & \multicolumn{3}{|c|}{ gestational age $<35 \mathrm{wks}$} & \multicolumn{3}{|c|}{ gestational age $\geq 35 \mathrm{wks}$} \\
\hline & $\mathbf{n}$ & PIVH & incidence (\%) & $\mathbf{n}$ & PIVH & incidence (\%) \\
\hline \multirow{2}{*}{$\begin{array}{l}\text { corticosteroid use } \\
\text { non corticosteroid use }\end{array}$} & 155 & 82 & 52.9 & 51 & 17 & 33.3 \\
\hline & 597 & 399 & 66.8 & 319 & 121 & 37.9 \\
\hline$x^{2}$ & & & 4.30 & & & 0.180 \\
\hline $\mathrm{P}$ & & & 0.038 & & & 0.671 \\
\hline
\end{tabular}

Table 3. Correlation between maternal perinatal complications and PIVH

\begin{tabular}{|l|c|c|c|c|c|c|}
\hline \multirow{2}{*}{ Groups } & \multicolumn{3}{|c|}{ gestational age<35weeks } & \multicolumn{3}{c|}{ gestational age $\geq 35 w e e k s$} \\
\cline { 2 - 7 } & $\mathbf{n}$ & PIVH & incidence (\%) & n & PIVH & incidence (\%) \\
\hline \multirow{2}{*}{ MPC } & 187 & 138 & 73.8 & 117 & 46 & 39.3 \\
\cline { 2 - 7 } Non-mpc & 567 & 346 & 61.0 & 251 & 39.5 \\
\hline$\chi^{2}$ & \multicolumn{7}{|r|}{0.038} & & 0.380 \\
\hline P & \multicolumn{3}{|c|}{0.540} \\
\hline
\end{tabular}


infants (HTI). The results showed that changes in platelet parameters may be involved in the pathogenesis of $\mathrm{PIVH}$ in premature infants (Table 4).

\section{Discussion}

The results of the present study indicate that the incidence of neonatal PIVH in China is much higher than previously reported incidences in developed countries (4-10). The lower the birthweights, the higher is the incidence rate in PIVHs, especially for those infants with birthweights of $<2000 \mathrm{~g}$. This maybe mainly because the lower birthweight, the lower gestational ages the babies have, and accordingly the more premature in subependymal germinal matrix. Thus we think the screening cutoff point of a birth weight of $2000 \mathrm{~g}$ seems to be more adequate than $1500 \mathrm{~g}$ which was commonly used in China. PIVH in premature infants is an important cause of mortality and is associated with long-term morbidity including neurodevelopmental problems such as hydrocephalus, cerebral palsy, learning disabilities, language barrier, delayed mental development, severe behavioral problems and so on. Particularly in those infants with high grade hemorrhage, early onset PIVH is also likely to be severe and to progress to a higher grade. According to the results of this study, low gestational age, low birth weight, mechanical ventilation, hypoxia, acidosis, hypercapnia, hypothermia, hypoglycemia, hyperlactacidemia, maternal perinatal complications, fetal distress and birth asphyxia were the most important risk factors for PIVH. Premature rupture of fetal membranes (PROM) is also a common cause of PIVH which may be correlated with conditions of ascending intrauterine infection caused by PROM, and it is well known that inutero exposure to bacterial infection increases the incidence of PIVH in immature newborn infants (11), and the inflammation and cytokines play an important role in the pathogenesis of brain damages $(11,12)$. The more premature infants have a higher incidence, experiencing more severe $\mathrm{PIVH}$, may be mainly because of low use of steroids, more premature in subependymal germinal matrix and Choroid Plexus Capillaries, etc. Serum osmolality, multiple births and cesarean section were not significantly correlated with the incidence of PIVH in premature infants. Maternal antenatal administration of vitamin $\mathrm{K}_{1}$ or corticosteroids can significantly decrease the incidence of PIVH $(13,14)$, and can be used routinely for women at risk of premature birth at $<35$ weeks of gestation. Antenatal supplementation with vitamin $\mathrm{K}_{1}$ may significantly increase the plasma activities of factors II, VII and $\mathrm{X}$, and consequently decrease the incidence of PIVH and lower the severity of hemorrhage. The immaturity of subependymal germinal matrix is the basic cause of PIVH in premature infants, when there is no intact basement membrane or only a basement-like material. Previous study showed use of antenatal corticosteroid can improve the maturation of subependymal germinal matrix (15). Thus, the incidence and the degree of $\mathrm{PIVH}$ in preterm infants before 35 weeks gestational age can be decreased significantly.

The present study also found that changes in platelet parameters, especially low platelet counts and a low thrombocytocrit, may be involved in the pathogenesis of PIVH in premature infants. It is important to monitor the changes in these platelet parameters in premature infants after birth.

Postnatal administration of phenobarbital for the prevention of PIVH has been used for more than two decades, but its effects have remained controversial. A previous meta-analysis revealed no differences between a phenobarbital-treated group and a control group for PIVH incidence, severe PIVH, posthemorrhagic ventricular dilatation, severe neurodevelopmental impairment and death before hospital discharge (16). Therefore, this strategy cannot be recommended as a prophylactic procedure for preventing $\mathrm{PIVH}$ in preterm infants and was found to be associated with an increased need for mechanical ventilation (16). Our present results showed that, although the total incidence of PIVH did not differ between the phenobarbital-treated and control groups, phenobarbital administration appeared to be effective for decreasing the severity of PIVH in preterm infants delivered at $<35$ weeks of gestation. Hence, we believe that phenobarbital administration may still have some benefits for the prevention of PIVH in premature infants.

In conclusion, many high risk factors were involved in the incidence of PIVH in preterm infants. The incidence of $\mathrm{PIVH}$ in preterm infants in China was much higher than the previously reported incidences in developed countries, especially for infants with birthweights of $<2000 \mathrm{~g}$. Therefore, we suggest that a new cutoff point of $2000 \mathrm{~g}$, rather than $1500 \mathrm{~g}$, should be used in China to assess the risk of PIVH based on birthweight. The present investigation provides a working protocol for PIVH diagnosis, prevention and treatment in premature newborn infants at risk.

\section{Conflict of interest}

None declared

Table 4. The correlation of the parameters of platelet and the incidence of PIVH $(\mathrm{X} \pm \mathrm{S})$

\begin{tabular}{|l|c|c|c|c|c|}
\hline Groups & $\mathbf{n}$ & PLT $(\times \mathbf{1 0} / \mathbf{L})$ & PCT (\%) & MPV (fl) & PDW (\%) \\
\hline HTI & 50 & $299.6 \pm 80.5$ & $0.254 \pm 0.09$ & $8.55 \pm 1.32$ & $17.5 \pm 0.83$ \\
\hline Non-PIVH & 60 & $239.5 \pm 86.5$ & $0.189 \pm 0.09$ & $8.27 \pm 1.15$ & $17.6 \pm 1.04$ \\
\hline PIVH & 100 & $175.7 \pm 78.8$ & $0.139 \pm 0.06$ & $8.46 \pm 1.17$ & $17.7 \pm 1.26$ \\
\hline F & & 31.84 & 28.64 & 0.70 & 0.46 \\
\hline p & & $<0.001$ & $<0.001$ & 0.497 & 0.632 \\
\hline
\end{tabular}




\section{References}

1. van de Bor M, Ens-Dokkum M. Schreuder AM, Veen S, Brand R, Verloove-Canhorick SP.. Outcome of periventricular- intraventricular hemorrhage at five years of ages. Dev Med Child Neurol,1993; 35: 33-41.

2. Vohr B, Ment LR. Intraventricular hemorrhage in the preterm infant. Early Hum Dev, 1996; 44: 1-16.

3. van de Bor M, den Ouden L. School performance in adolescents with and without periventricular- intraventricular hemorrhage in the neonatal period. Semin Perinatol,2004; 28: 295-303.

4. van de Bor M, Van Bel F, Lineman R, Ruys JH. Perinatal factors and periventricular-intraventricular hemorrhage in preterm infants. Am J Dis Child, 1986; 140: 1125-30.

5. van de Bor M, Verloove-Vanhorick SP, Brand R, Keirse MJ, Ruys JH. Incidence and prediction of periventricular-intraventricular hemorrhage in very preterm infants. J Perinat Med,1987; 15: 333-9.

6. Philip AG, Allan WC, Tito AM, Wheeler LR. Intraventricular hemorrhage in preterm infants: Declining incidence in 1980's. Pediatrics, 1989; 84: 797-801.

7. Hack M, Wright LL, Shankaran S, Tyson JE, Horbar JD, Bauer CD, et al. Very-low-birthweight outcomes of the National Institute of Child Health and Human Development Neonatal Network,November 1989 to October 1990. Am J Obstet Gynecol, 1995; 172: 457-64.

8. Volpe JJ. Intracranial hemorrhage: Germinal matrix-intraventricular hemorrhage of the remature infant, Volpe JJ (ed): Neurology of the Newborn (4th ed) Philadelphia, WB Saunders, 2001; 428-93.

9. Papile LA, BursteinJ, Burstein R, Koffler H. Incidence and evolution of subepemdymal and intraventricular hemorrhage: A study of infants with birth weights less than 1500 grams. J Pediatr,1978; 92: $529-34$.
10. Cherpelli JL, Santos Filho AS, Silveira JD, Tani ME, Costa HP. Incidence of peri-intraventricular hemorrhage in preterm newborn infants with birth weight less than 1500 gms: evaluation of brain ultrasonographic studies and necropsy. Arg Neuropsiquiatr,1992; 50: $284-8$

11. Garnier Y. The significance of fetal inflammation in the pathogenesis of perinatal brain injury. Journal of The Turkish German Gynecological Association, 2004; 5: 193-202.

12. Liu J, Cao HY, Meng FH, Rong Px. The Role and Mechanisms of IL-6, IL-8 and TNF- $\alpha$ for regulating cerebral hemodynamics in term infants with hypoxic-ischemic encephalopathy. Journal of The Turkish German Gynecological Association,2007; 8: 63-6.

13. Liu J, Wang Q, Gao F, He JW, Zhao JH. Maternal antenatal administration of vitamin $\mathrm{K} 1$ results in increasing the activities of vitamin $\mathrm{K}$ dependent coagulation factors in umbilical blood and in decreased the incidence rate of Periventricular-intraventricular hemorrhage in premature infants. J Perinat Med 2006; 34: 173-6.

14. Liu J, Wang Q, Zhao JH, Chen YH, Qin GL. The Combined Antenatal Corticosteroids and Vitamin K Therapy for Preventing Periventricular-intraventricular Hemorrhage in Premature Newborns Less Than 35 Weeks Gestation. J Trop Pediatr, 2006; 52: 355-9.

15. Liu J, Feng ZC,Yin XJ, Chen H, Lu J, Qiao X. The role of antenatal corticosteroids for improving the maturation of choroid plexus capillaries in fetal mice. Eur J Pediatr,2008; 167: 1209-12.

16. Whitelaw A, Odd D. Postnatal phenobarbital for the prevention of intraventricular hemorrhage in preterm infants. Cochrane Database Syst Rev, 2007; 4: CD001691. 